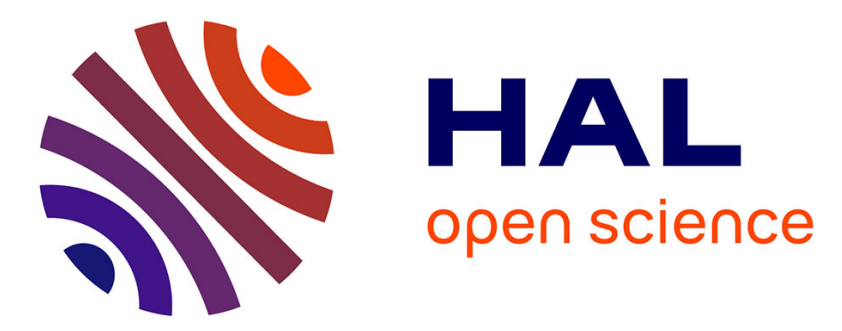

\title{
Bumetanide, an NKCC1 antagonist, does not prevent formation of epileptogenic focus but blocks epileptic focus seizures in immature rat hippocampus.
}

\author{
Romain Nardou, Yehezkel Ben-Ari, Ilgam Khalilov
}

\section{- To cite this version:}

Romain Nardou, Yehezkel Ben-Ari, Ilgam Khalilov. Bumetanide, an NKCC1 antagonist, does not prevent formation of epileptogenic focus but blocks epileptic focus seizures in immature rat hippocampus.. Journal of Neurophysiology, 2009, 101 (6), pp.2878-88. 10.1152/jn.90761.2008 . inserm-00483209

\section{HAL Id: inserm-00483209 https://www.hal.inserm.fr/inserm-00483209}

Submitted on 12 May 2010

HAL is a multi-disciplinary open access archive for the deposit and dissemination of scientific research documents, whether they are published or not. The documents may come from teaching and research institutions in France or abroad, or from public or private research centers.
L'archive ouverte pluridisciplinaire HAL, est destinée au dépôt et à la diffusion de documents scientifiques de niveau recherche, publiés ou non, émanant des établissements d'enseignement et de recherche français ou étrangers, des laboratoires publics ou privés. 


\title{
Bumetanide, an NKCC1 Antagonist, Does Not Prevent Formation of Epileptogenic Focus but Blocks Epileptic Focus Seizures in Immature Rat
}

\section{Hippocampus}

\author{
Romain Nardou, Yehezkel Ben-Ari and Ilgam Khalilov \\ Institut de Neurobiologie de la Méditerranée, Institut National de la Santé et de la Recherche Médicale Unité 901 and Université de la \\ Méditerranée, Marseille, France
}

Submitted 11 July 2008; accepted in final form 10 March 2009

Nardou R, Ben-Ari Y, Khalilov I. Bumetanide, an NKCC1 antagonist, does not prevent formation of epileptogenic Focus but blocks epileptic focus seizures in immature rat hippocampus. $J$ Neurophysiol 101: 2878-2888, 2009. First published March 18, 2009; doi:10.1152/jn.90761.2008.

Excitatory GABA action induced by high $\left[\mathrm{Cl}^{-}\right]_{\mathrm{i}}$ is thought to contribute to seizure generation in neonatal neurons although the mechanism of this effect remains unclear. We report that bumetanide, a NKCC1 antagonist, reduces driving force of GABAmediated currents $\left(\mathrm{DF}_{\mathrm{GABA}}\right)$ in neonatal hippocampal neurons and blocks the giant depolarizing potentials (GDPs), a spontaneous pattern of network activity. In the preparation composed of two intact interconnected hippocampi, bumetanide did not prevent generation of kainate-induced seizures, their propagation to the contralateral hippocampus, and formation of an epileptogenic mirror focus. However, in the isolated mirror focus, bumetanide effectively blocked spontaneous epileptiform activity transforming it to the GDP-like activity pattern. Bumetanide partially reduced $\mathrm{DF}_{\mathrm{GABA}}$ and therefore the excitatory action of GABA in epileptic neurons. Therefore bumetanide is a potent anticonvulsive agent although it cannot prevent formation of the epileptogenic mirror focus. We suggest that an additional mechanism other than NKCC1-mediated contributes to the persistent increase of $\mathrm{DF}_{\mathrm{GABA}}$ in epileptic neurons.

\section{INTRODUCTION}

GABA - the principal inhibitory neurotransmitter in adultsexcites immature neurons because of a higher $\left[\mathrm{Cl}^{-}\right]_{\mathrm{i}}$ in different animal species and brain structures (Ben-Ari 2002).

This difference is thought to play an important role in higher incidence of seizures early in life in humans (Hauser 1995; Moshe et al. 1983), lower seizure threshold in experimental animals, and higher neuronal excitability (Holmes and Ben-Ari 1998; Khazipov et al. 2004).

This early elevated $\left[\mathrm{Cl}^{-}\right]_{\mathrm{i}}$ is due to a sequential development of two chloride co-transporters: NKCC1, which imports chloride, and KCC2, which extrudes it (Kahle and Staley 2008a,b; Mikawa et al. 2002; Shimizu-Okabe et al. 2002; Wang et al. 2002). Several observations suggest a link between the excitatory action of GABA and seizure generation at an early developmental stage (Dzhala and Staley 2003; Khazipov et al. 2004).

Other observations suggest that bumetanide, a NKCC1 antagonist,

Address for reprint requests and other correspondence: Y Ben-Ari, INMED U901 INSERM, 163, route de Luminy, 13273 Marseille Cedex 09, France (Email ben-ari@inmed.univ-mrs.fr ) attenuates epileptiform activity in the immature rodent hippocampus by reducing $\left[\mathrm{Cl}^{-}\right]_{\mathrm{i}}$. The effects of bumetanide were observed neither in NKCC1 knock-out mice nor when GABA receptors were blocked, confirming the importance of $\left[\mathrm{Cl}^{-}\right]_{\mathrm{i}}$ accumulation (Dzhala et al. 2005). However, bumetanide was efficient against seizures acutely induced in vitro by some convulsants but not by others (Kilb et al. 2007), indicating that in the latter case a NKCC1-independent mechanism was involved in seizure generation. Epilepsy is, however, a chronic disorder associated with permanent changes of several signaling cascades. Acute seizures models only partly reflect multiple events that occur in the epileptic network and are less relevant to the clinical situation.

Excitatory actions of GABA have been reported in adult human epileptic temporal lobe neurons (Cohen et al. 2002; Huberfeld et al. 2007) and in chronic epileptic foci in animal models (Khalilov et al. 2003, 2005). Presumably, a gradual accumulation of intracellular chloride during recurrent seizures caused these GABA effects. It is therefore important to define a link between seizures, alterations in $\left[\mathrm{Cl}^{-}\right]_{\mathrm{i}}$, and epileptogenesis.

We studied these issues in the intact interconnected hippocampal formation (IIHF). Using this preparation in a three-compartment chamber (Khalilov et al. 1999), we were able to initiate seizures in one hippocampus and then to investigate the effects of drugs on both the seizure propagation to other hippocampus and seizure-induced epileptogenic mirror focus formation (Khalilov et al. 2003, 2005) in that hippocampus.

Our first aim was to investigate whether bumetanide acts as an antiepileptogenic agent and therefore prevents formation of the epileptogenic mirror focus by seizures. If this is not the case, bumetanide can still block seizures in the mirror focus and thus to cause an anticonvulsive effect.

The second aim was to investigate the role of NKCC1 in an increased neuronal $\left[\mathrm{Cl}^{-}\right]_{\mathrm{i}}$ in epileptogenic mirror foci.

Because it recently has been shown that the invasive recordings provide inadequate measures of the resting membrane potential $\left(E_{\mathrm{m}}\right)$ (Tyzio et al. 2003) and the perforated-patch technique may cause systematic errors in measurements of the reversal potential of GABA-induced currents $\left(E_{\mathrm{GABA}}\right)$ (Brumback and Staley 2008), we used noninvasive single $N$-methyl-D-aspartate (NMDA) and GABA channel recordings to determine, respectively, $E_{\mathrm{m}}$ and $E_{\mathrm{GABA}}$.

\section{METHODS}

Experiments were performed on neonatal Wistar rats (postnatal days P7-P8). All experiments have been carried out in accordance with the European Communities Council Directive of 24 November 1986 (86/609/EEC). 


\section{Hippocampal preparation}

The interconnected intact hippocampal formations were prepared as described previously (Khalilov et al. 1997.). In brief, neonatal Wistar rats were decapitated after hypothermic anesthesia, and the brain rapidly removed to oxygenated $\left(95 \% \mathrm{O}_{2}-5 \% \mathrm{CO}_{2}\right)$ ice-cold artificial cerebrospinal fluid (ACSF). Complexes including two interconnected hippocampi were isolated and transferred into a beaker with oxygenated ACSF containing (in mM) $126 \mathrm{NaCl}, 3.5$ $\mathrm{KCl}, 2.0 \mathrm{CaCl}_{2}, 1.3 \mathrm{MgCl}_{2}, 25 \mathrm{NaHCO}_{3}, 1.2 \mathrm{NaH}_{2} \mathrm{PO}_{4}$, and 11 glucose $(\mathrm{pH} 7.4)$ and incubated $1 \mathrm{~h}$ before use. The intact hippocampal formations were placed into the conventional fully submerged three-compartment chamber (Fig. 3, see diagram) and superfused with oxygenated ACSF $\left(30-32^{\circ} \mathrm{C}, 10-15 \mathrm{ml} / \mathrm{min}\right)$. The hippocampi were fixed by entomological needles to the silicone elastomer (Sylgard)-covered bottom.

\section{Slice preparation}

Slices were prepared as described previously (Ben-Ari et al. 1989). In brief, after decapitation, the brain was rapidly removed and placed in oxygenated, ice-cooled ACSF; hippocampal transverse slices $(500 \mu \mathrm{m})$ were cut with a McIIwain tissue chopper and kept in oxygenated ACSF at room temperature for $1 \mathrm{~h}$ before use. Individual slices were then transferred to the recording chamber where they were fully submerged and superfused with oxygenated ACSF (30$\left.32^{\circ} \mathrm{C}, 2-3 \mathrm{ml} / \mathrm{min}\right)$.

\section{Electrophysiological recordings}

All recordings were made from CA3 pyramidal layer. Whole cell patch-clamp recordings in voltage- or current-clamp configuration were collected using an Axopatch 200B amplifier (Axon Instruments). Patch pipette solution were: 1 ) for recordings of single GABA(A) channels containing (in mM) $120 \mathrm{NaCl}, 20$ TEA-Cl, 5 $\mathrm{KCl}, 5$ 4-aminopyridine, $0.1 \mathrm{CaCl}_{2}, 10 \mathrm{MgCl}_{2}, 10$ glucose, 10 HEPES-NaOH buffered to $\mathrm{pH} 7.2-7.3$ and $1 \mu \mathrm{M}$ GABA; 2) for recordings of single NMDA channels: nominally $\mathrm{Mg}^{2+}$-free ACSF with $10 \mu \mathrm{M}$ NMDA and $1 \mu \mathrm{M}$ glycine; 3) for whole cell recordings (in mM): $140 \mathrm{CsCl}, 1 \mathrm{CaCl}_{2}, 10$ EGTA, 10 HEPES, $2 \mathrm{MgATP}$, and 0.4 GTP, pH 7.25, osmolarity 280, patch pipettes had a resistance of 8-10 M; 4) for gramicidin perforated-patch recording (in mM): 150 $\mathrm{KCl}$ and 10 HEPES, buffered to $\mathrm{pH} 7.2$ with Tris-OH. Gramicidin was first dissolved in DMSO to prepare a stock solution of $40 \mathrm{mg} / \mathrm{ml}$ and then diluted to a final concentration of $80 \mu \mathrm{g} / \mathrm{ml}$ in the pipette solution. The gramicidin-containing solution was prepared $30 \mathrm{~min}$ before the experiment. Patch pipettes were filled with a gramicidincontaining solution, and then the tip was dipped into and filled with a gramicidin-free solution by applying a negative pressure for 30-40 $\mathrm{s}$ to facilitate cell-attached formation (4-10 G). Twenty to $30 \mathrm{~min}$ after cell-attached formation, series resistance decreased and stabilized. At the end of each recording, negative pressure applied to break the membrane and establish whole cell configuration. This was associated with a shift of the reversal potential of the $\mathrm{GABA}_{\mathrm{A}}$ mediated responses to near $0 \mathrm{mV}$. Cells were identified by adding biocytin (0.4\%) to the pipette solution for morphological analysis.

Extracellular potentials were recorded using two types of electrodes: field recordings were made with glass micropipettes (GC120TF-10, Clark Electromedical Instruments) filled with ACSF (1-5 M); and to record multiunit activity (MUA), we used tungsten wire electrodes (diameter: $50 \mu \mathrm{m}$, California Fine Wire, Grover Beach, CA). Recording electrodes were positioned in a pyramidal cell layer of CA3 subfield, and signals were amplified using a custom-made DAM-8A amplifier (WPI, GB; low filter: $0.1 \mathrm{~Hz}$; high filter: $3 \mathrm{kHz}$; 1,000$)$. Electrical stimulations were made with a bipolar electrode (10-20 V, $40 \mu \mathrm{s})$.

Synaptic responses were acquired using an A/D converter (Digidata 1440A, Axon Instruments). Axoscope and Clampfit 10.1 (Axon Instruments) and Origin 7.0 (Microcal Software) programs were used for the acquisition and analysis of the synaptic activities. Group measures are expressed as means $\pm \mathrm{SD}$, error bars also indicate SD. Statistical significance of differences was assessed with the Student's $t$-test, the level of significance was set at $P<0.05$. Drugs used were purchased from Sigma [tetrodotoxin (TTX), bumetanide, gramicidin], Tocris [bicuculline, gabazine, 6-cyano-7nitroquinoxaline-2,3 dione (CNQX), D-2-amino-5phosphopentanoate (APV)] and Molecular Probes (biocytin).

\section{RESULTS}

Bumetanide reduces the excitatory GABA action and blocks GDPs in naïve neurons

We first tested the actions of bumetanide on activity of immature hippocampal neurons with simultaneous extracellular and gramicidin perforated patch-clamp recordings (Fig. 1). Neuronal activity at early developmental stages is characterized by spontaneous networkdriven discharges, so-called giant depolarizing potentials (GDPs) (Ben-Ari et al. 1989), consisting predominantly of GABAergic postsynaptic currents (PSCs) and bursts of MUA in field potential recordings (Fig. 1Aa). As in earlier observations (Sipila et al. 2006), bumetanide $(10 \mu \mathrm{M})$ blocked spontaneous and evoked GDPs (Fig. 1Ba). In control, single-electrical stimulation evoked a burst of action potentials and large GDPs (Fig. 1Aa). Addition of bumetanide strongly reduced both the number of action potentials (from $65.7 \pm$ 16.9 to $8 \pm 2.6$ spike, $n=17$ ) and the amplitude of evoked PSCs(Fig. $1, B a$ and $C)$. In the presence of APV $(40 \mu \mathrm{M})$ and CNQX $(10 \mu \mathrm{M})$, evoked PSCs were considerably reduced, but a few spikes (5.1 \pm 1.7 spike, $n=17$ ) were still present (Fig. $1, A b$ and $C$ ). These spikes were blocked by further addition of bicuculline (Fig. 1, Ac and $C$ ), confirming the contribution of excitatory GABAergic synapses in their generation. While bicuculline-sensitive spikes could be generated in the presence of glutamate receptors antagonists, they were not generated in the presence of bumetanide (Fig. 1Bb). Therefore bumetanide was as efficient as bicuculline in blocking the GABA-mediated spiking activity.

Relying on $I-V$ relations of single NMDA and GABA channels (Fig. 2A), we then determined the alterations in $\mathrm{DF}_{\mathrm{GABA}}$ produced by bumetanide. As shown in Fig. 2, $B$ and $C$ (left), bumetanide did not change $E_{\mathrm{m}}(-78.5 \pm 2.3$ and $-79.8 \pm 3.2 \mathrm{mV}, n=9$ and $n=13$, respectively, $P=0.5$ ). However, bumetanide decreased $\mathrm{DF}_{\mathrm{GABA}}$ (from $13.7 \pm 11.6$ to $2.02 \pm 4.8 \mathrm{mV}, n=8$ and $n=10$, respectively, $P$ $<0.01$ ) and thus negatively shifted $E_{\mathrm{GABA}}$. Therefore bumetanide reduced $\left[\mathrm{Cl}^{-}\right]_{\mathrm{i}}$ leading to a less depolarized $\mathrm{DF}_{\mathrm{GABA}}$ and blockade of GDPs.

Bumetanide does not block generation and propagation of kainateinduced seizures

We then tested the effects of bumetanide on the generation and propagation of seizures induced by unilateral application of kainate using the IIHF in three-compartment chamber Fig. 3A (left). In keeping with our earlier observations (Khalilov et al. 2003), a single application of kainate (300-400 nM) generated recurrent ictal events that propagated from the kainate-treated hippocampus to the contralateral one (Fig. 3A). As shown in Fig. 3A (right), these paroxysmal discharges included high-frequency oscillations (HFOs; $50-150 \mathrm{~Hz}$ ) in both treated (not shown) and naïve hippocampi. As 
A
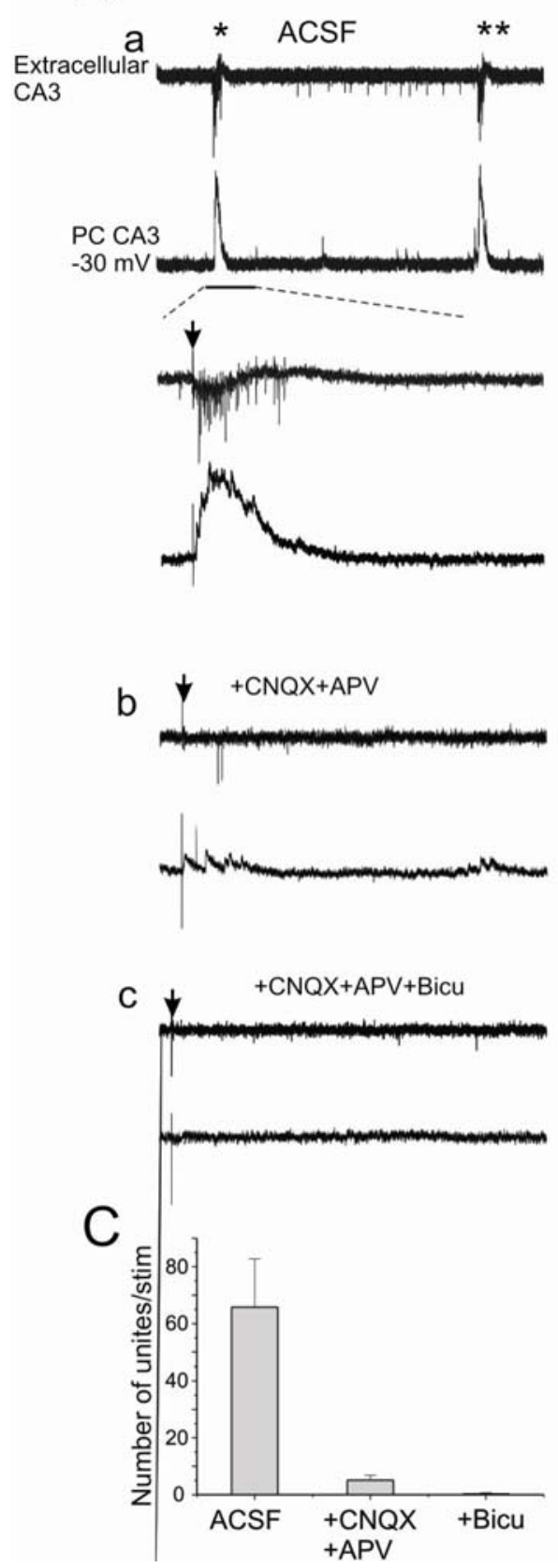

B

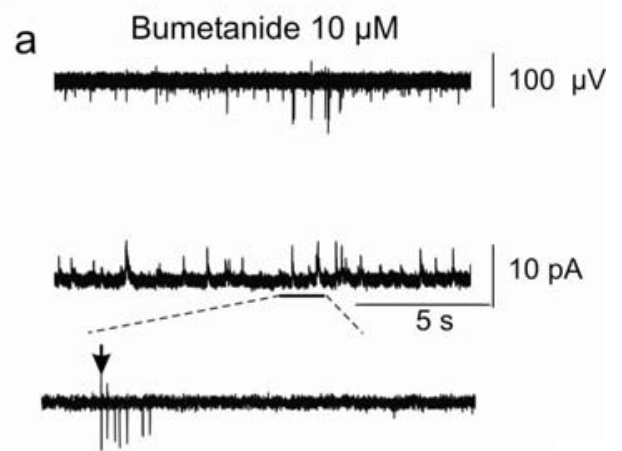

FIG. 1. Bumetanide blocks GABA-mediated excitation and GDPs in neonatal rat hippocampus. Dimultaneous extracellular and gramicidin-perforated patch-clamp recordings in the CA3 pyramidal layer of hippocampus in artificial cerebrospinal fluid (ACSF, $A$ ) and ACSF + bumetanide (Bum; B). $A b$ and $B b$ : similar recordings in the presence of 6-cyano-7nitroquinoxalene-2,3-dione (CNQX) and D-2amino-5-phosphopentanoate (APV). Note that glutamatergic receptor antagonists blocked $100 \%$ of the evoked (arrows) multiunit activity (MUA) in the bumetanide treated slices and only $\sim 90 \%$ in control. $A c$ and $B c$ : the remaining activity was completely blocked by the GABAergic receptor antagonist bicuculline (Bicu) confirming the excitatory action of GABA in naïve neurons. $C$ : summary plot of the mean number of units evoked by a single stimulus (15-20 stimuli per slice) in 4 independent experiments. long as the two hippocampi were connected, continuous application of bumetanide $(10 \mu \mathrm{M})$ to the contralateral naïve hippocampus-in parallel with recurrent applications of kainate to the treated sidedid not reduce the severity of ictal events in both hippocampi as indicated by the HFOs (Fig. 3B, right) and power spectrum (Fig. 3D; $n=7$ ). In fact, continuous application of bumetanide to both hippocampi while kainate was applied to one hemisphere also failed to reduce seizure severity in both kainate treated and contralateral side (not shown, $n=3$ ). Higher concentrations of bumetanide (50 $\mu \mathrm{M}$ ) failed to reduce seizure severity (not shown, $n=3$ ) as well.

Bumetanide does not prevent formation of a mirror focus but blocks seizure generation in the mirror focus
To form an epileptogenic mirror focus, we used recurrent applications of kainate (15 times) to one hippocampus (ipsilateral, ipsi-) that generated an epileptic focus in the connected hippocampus (contralateral, contra-) (Khalilov et al. 2003, 2005). With this protocol, naive hippocampus (contra-) became epileptic and generated seizures after disconnection from the kainate treated side for 2 days (Khalilov et al. 2003., 2005.). In these experiments, in parallel with recurrent kainate applications, bumetanide was continuously applied to the contralateral hippocampus. Following repeated applications of kainate, both hippocampi generated spontaneous and synchronous ictal-like seizures in spite of the presence of bumetanide (Fig. 4A). Interestingly, analyses of the inter-hemispheric latencies revealed that each spontaneous ictal event always originated initially from the ipsilateral hippocampus 
NMDA

A

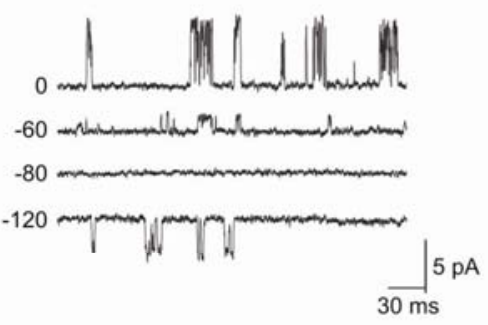

B

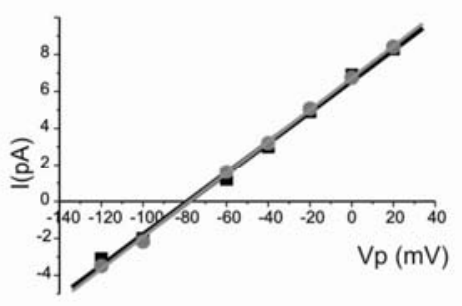

C

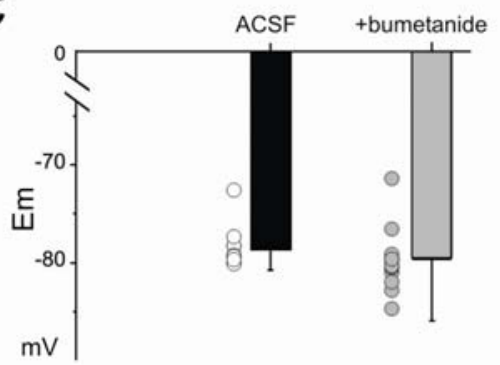

GABA

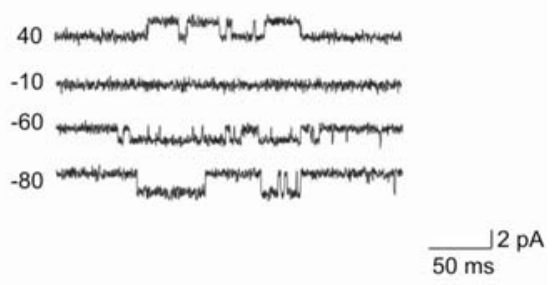

FIG. 2. Bumetanide strongly reduces the depolarizing driving force of GABA-mediated currents $\left(\mathrm{DF}_{\mathrm{GABA}}\right)$. A: cell-attached recordings of single $\operatorname{GABA}(A$; left $)$ and $N$-methyl-Daspartate (NMDA) receptor channels (right) in CA3 pyramidal cells in control ACSF. $B: I-V$ relationships of single $\mathrm{GABA}_{\mathrm{A}}$ and NMDA receptor channels in ACSF (W) and bumetanide-treated $(-)$ slices. $C$ : summary plot of the resting membrane potential $\left(E_{\mathrm{m}}\right)$ and driving force of GABA-mediated currents $\left(\mathrm{DF}_{\mathrm{GABA}}=E_{\mathrm{GABA}}-E_{\mathrm{m}}\right)$ in control $(\mathrm{O})$ and in bumetanide (O). Each circle corresponds to 1 CA3 pyramidal cell. Error bars indicate SD.
(Fig. $4 \mathrm{Ab}, \mathrm{n}=5$ ) that was not the case during tonic-clonic and clonic phases of the event (Figs. 4A, c and d, $n=40$ ).

We then disconnected the two hippocampi by severing the commissural fibers (not shown) or by applying TTX to the commissural chamber (Fig. 4B) while the contralateral hippocampus was still exposed to bumetanide. We observed that seizures were generated in the kainate-treated hippocampus only. The bumetanidetreated side failed to generate the epileptiform activity (Fig. 4B, $n=$ 4), generating instead the synchronized events reminiscent to GDPs (named further as epileptic GDPs, EGDPs). However, after washing out of bumetanide, spontaneous and evoked seizures reappeared (Fig. 4C). In additional experiments, continuous application of bumetanide to both hippocampi while kainate was repeatedly applied to only one, failed also to prevent the formation of epileptogenic foci in both hippocampi ( $n=4$, not shown). Therefore bumetanide prevented neither the long-term effects of kainate nor transformation by propagating seizures the naive hippocampus to one generating seizures.

Bumetanide restores GDP-like recurrent population bursts in the mirror focus

We then investigated the electrical properties of the disconnected mirror focus more detail. Field and patch-clamp recordings were made from the isolated mirror focus in intact hippocampi and in slices prepared from such hippocampus, which also were able to generate spontaneous epileptiform events (Khalilov et al. 2003). The isolated intact hippocampus generated spontaneously ictal and interictal events that were fully blocked by bumetanide (Fig. $5 \mathrm{~A}, n=$ 7). Similar observations were made in slices prepared from the mirror foci (Fig. 5B, $n=9$ ). In the presence of bumetanide, the disconnected mirror focus generated EGDPs (see following text and Fig. 6). Bumetanide also blocked the induction of stimuli-induced epileptiform oscillations in the mirror focus (not shown, $n=10$ ). After washout, spontaneous and evoked epileptiform oscillations reappeared after various delays, suggesting that the permanent network alterations in the mirror focus were not abolished by bumetanide (Fig. 5B). Therefore bumetanide blocked seizure generation in the mirror focus but neither prevented formation of the mirror focus nor reversed the chronic epileptic features of the tissue. After addition of bumetanide, interictal activity was completely suppressed and replaced by recurrent population bursts of activity, EGDPs, that had a number of similar features with physiological patterns, GDPs, including (Fig. 6): both types of events were characterized by a few hundred millisecond increase in MUA with a relatively small delta-wave-like deflection of local field potentials in the pyramidal cell layer and without population spikes (Figs. 6Ba and $7 \mathrm{~A}, *)$; both population events had much smaller amplitudes than those of interictal events $(110 \pm 18.9 \mathrm{mV}$ for GDPs; $71.3 \pm 1.2$ $\mathrm{mV}$ for EGDPs, and $553.2 \pm 12.4 \mathrm{mV}$ for interictal events, $n=24, n$ $=27$, and $n=48$ events, respectively, $P<0.01$; Fig. 6D); in gramicidin perforated-patch recordings, both types of events had similar reversal potential $(60.9 \pm 3.1 ; 59.6 \pm 1.5 \mathrm{mV}$, and $36.9 \pm 4.6$ $\mathrm{mV}$ for interictal events, $n=10$; Fig. 6, $a$ and $b$ ); and estimated in cell-attached recordings, the number of spikes in CA3 pyramidal 

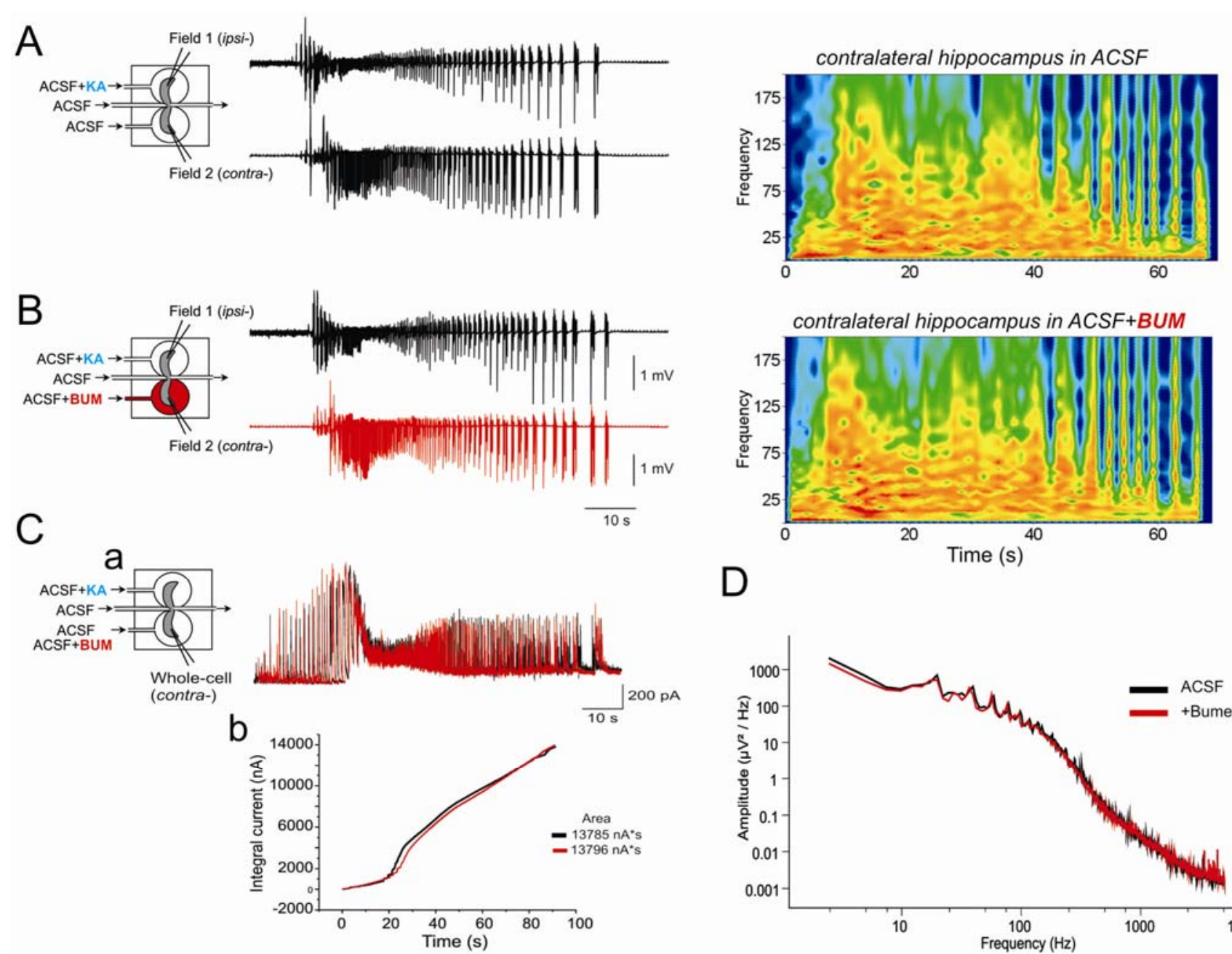

D

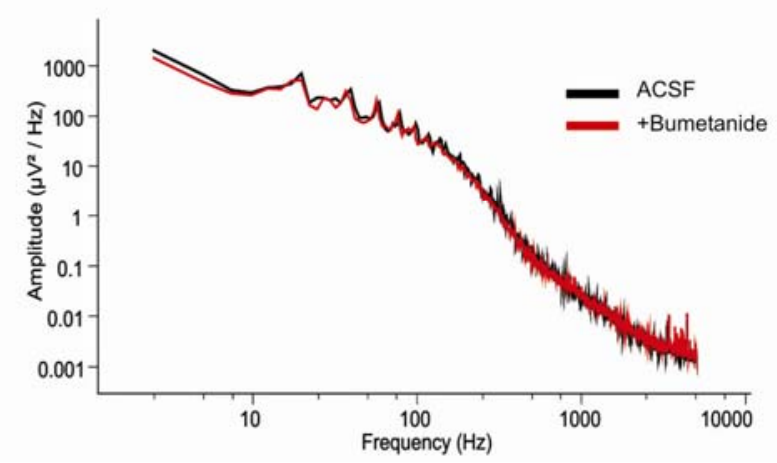

FIG. 3. Bumetanide does not block generation and propagation of kainate-induced seizures. Left: experimental design and the 3-compartment chamber. Two hippocampi and commissural connections have independent inlets and a common outlet. Kainate was applied to 1 hippocampus [ipsilateral (ipsi-)] and electrical activity recorded in ipsi- and contralateral hippocampus (contra-). A: kainic acid (300-400 nM) was applied briefly (3 min) to 1 compartment (ipsi-), whereas the contralateral compartment was perfused with normal ACSF. Seizures induced in the ipsilateral hippocampus propagate to the contralateral side. High-frequency oscillations (HFOs, 50-150 Hz) were observed in the contralateral hippocampus. These high-frequency activities were visualized by timefrequency (TF) representations using Wavelet analysis. Here field power is coded in colors so that red corresponds to higher frequency (right). B: kainate was applied to one hippocampus (ipsi-) and bumetanide $(10 \mu \mathrm{M})$ to the naïve contralateral hippocampus (contra-). Bumetanide did not block ictal-like events and HFOs in the contralateral hippocampus (TF representations and power spectrogram). C: perforated-patch recordings from a neuron in the contralateral treatment (red trace). $C b$ : integral currents calculated from $C a$. $D$ : power spectrum of field potentials during ictal events in control and in the presence of bumetanide.

cells was similar during GDPs (Fig. 6Ac) and EGDPs (Cc) but much bigger during interictal $(B c)$ activity (1-2 spikes for control or EGDPs and 4-5 for interictals; Fig. 6E).

Thus in spite of the fact that bumetanide eliminated epileptiform activity in the mirror focus some population activity, EGDPs, still remained, presumably due to a NKCC1-independent increase of $\left[\mathrm{Cl}^{-}\right.$ ]$_{\mathrm{i}}$ in epileptic neurons.

NKCC1 underlies only partially excitatory GABA action in epileptogenic neurons

Formation of the mirror focus is associated with a permanent increase in $E_{\mathrm{GABA}}$ (Khalilov et al. 2003). This and other observations (Cohen et al. 2002; Fujiwara-Tsukamoto et al. 2007; Jin et al. 2005; Rivera et al. 2004; for review, see Ben-Ari et al. 2007) suggest that recurrent seizures produce a permanent accumulation of chloride and therefore enhance the excitatory action of GABA.

As shown in Fig. 7, $A-D$, the excitatory actions of GABA in the mirror focus were reduced but not blocked by combined applications of bumetanide, APV, and CNQX. Bumetanide transformed stimuliinduced epileptiform oscillations to EGDPs (Fig. 7, $A$ and $B$ ). Evoked bursts of action potentials were still observed after application of APV and CNQX (Fig. 7C) and were completely blocked following application of bicuculline $(D)$, suggesting that in the presence of bumetanide, GABA still exerts an excitatory action mediated by NKCC1-independent mechanism(s).

To clarify this effect, we measured $E_{\mathrm{m}}$ and $\mathrm{DF}_{\mathrm{GABA}}$ in epileptic neurons. $E_{\mathrm{m}}$ was not significantly different in naïve neurons and neurons (Fig. 7E) in the mirror focus $(-78.1 \pm 1.8$ and $-74,8 \pm 2.3$ $\mathrm{mV}, n=14$ and $n=10$, respectively, $P=0.08$.

Bumetanide or glutamate receptor antagonists (CNQX+APV) blocked seizures but did not alter $E_{\mathrm{m}}$. In neurons of epileptic mirror foci, however, $\mathrm{DF}_{\mathrm{GABA}}$ was significantly increased (from $13.2 \pm 12.2$ 


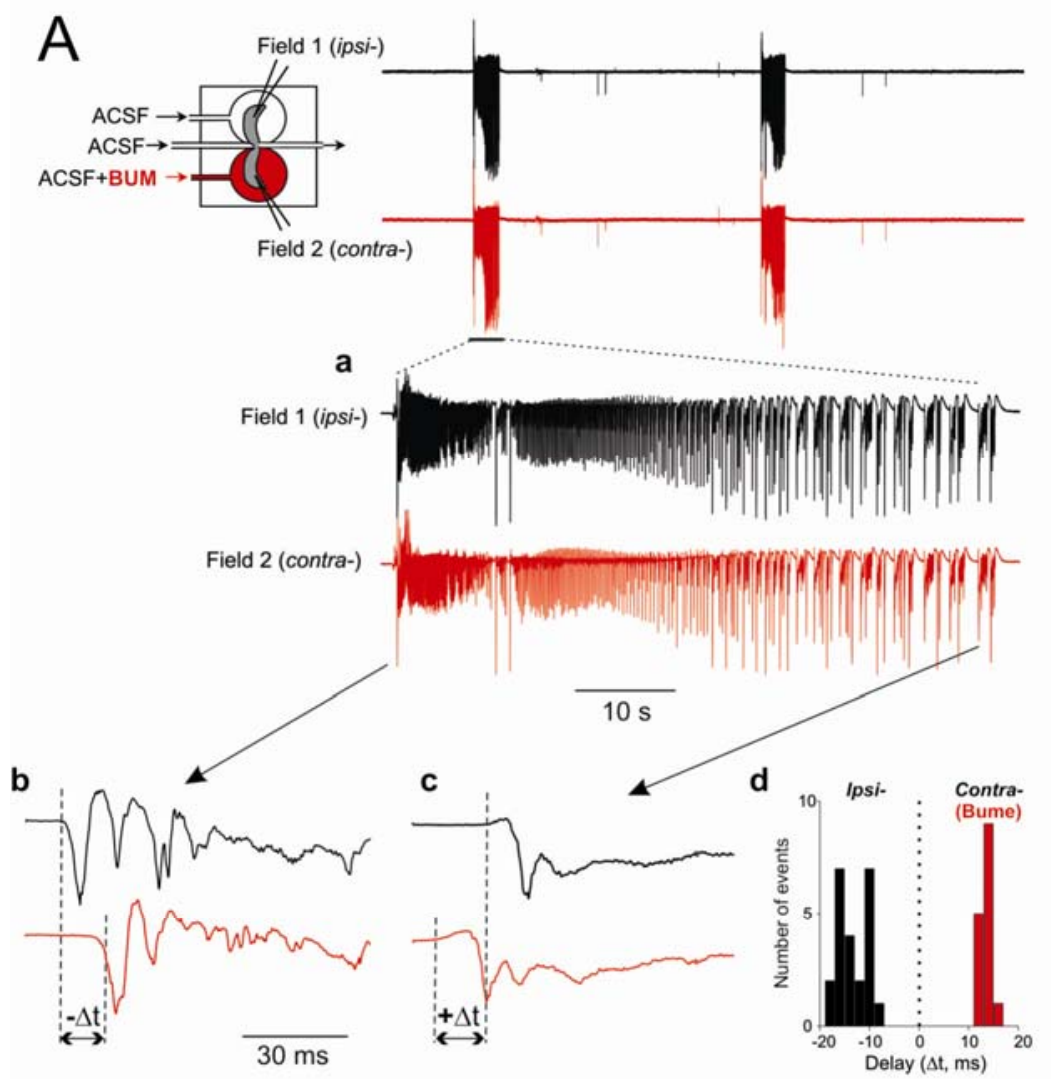

FIG. 4. Bumetanide does not prevent the formation of an epileptogenic mirror focus. A: simultaneous field recordings in the ipsilateral hippocampus exposed 15 times to kainate and contralateral hippocampus continuously exposed to bumetanide. Both hippocampi were connected and spontaneous seizures were synchronous. $A a$ : an epileptiform ictal-like activity depicted at larger scale. $A, b$ and $c$ : epileptiform events at the start and at the end (tonicclonic phase) of the ictal-like activity. Note that seizures originated always $(n=5)$ from ipsilateral hippocampus as shown in $A b$ at expended scale. During the tonic-clonic phase $(A c)$, this is not the case, as quantified in $A d$. $A d$ : quantification of the inter-hemispheric latencies $(\Delta t)$. B and $C$ : simultaneous field recordings following disconnection of 2 hemispheres by applying TTX onto commissural connections. $B$ : bumetanide is still present in the contralateral side. Seizures are not generated; however, GDP-like population activity still exists. C: after washing bumetanide out, both sides generate seizures that are not synchronous.
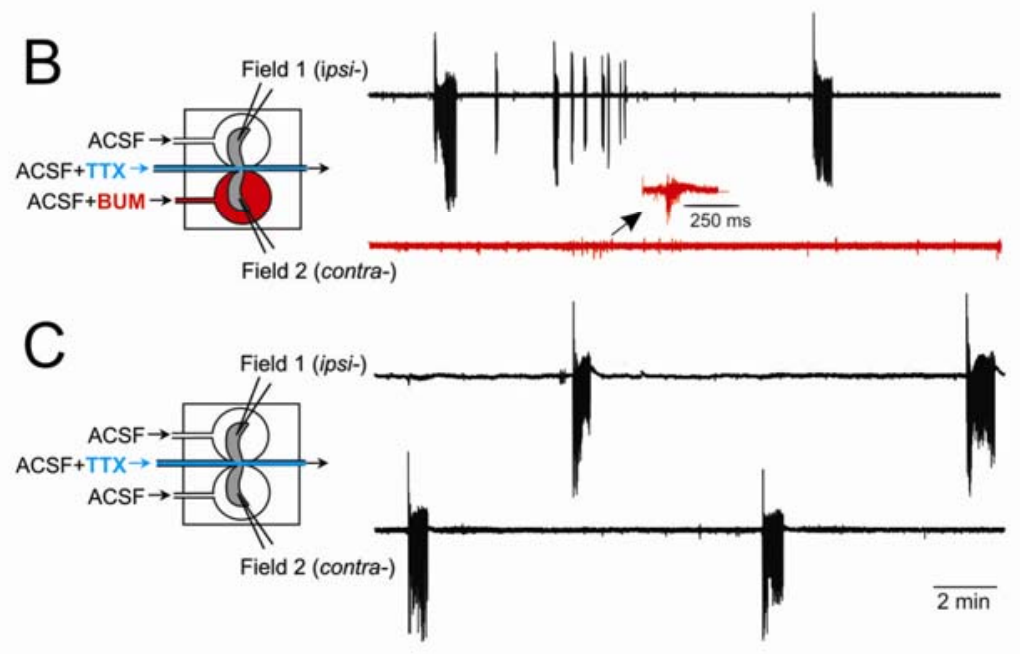

to $37.3 \pm 8.1 \mathrm{mV}, n=8$ and $n=33$, respectively, $P<0.001$ ) that resulted in a positive shift in $E_{\mathrm{GABA}}$ (Fig. 7F). Bumetanide significantly reduced this shift (from $37.3 \pm 8.1$ to $14.2 \pm 7.6 \mathrm{mV}, n=$ 33 and $n=17$, respectively, $P<0.001$ ), although values of $\mathrm{DF}_{\mathrm{GABA}}$ remained bigger than those in naïve neurons $(14.2 \pm 7.6$ vs. $2.02 \pm$ $4.8 \mathrm{mV}$ in naïve neurons in the presence of bumetanide; Figs. 7F and 2C). Increasing the bumetanide concentration $(50 \mu \mathrm{M}, n=8)$ or blockade of ongoing seizures by CNQX+APV failed to block this persistent increase of $\mathrm{DF}_{\mathrm{GABA}}$.

Therefore in the presence of bumetanide, $\mathrm{DF}_{\mathrm{GABA}}$ remained by $\sim 10 \mathrm{mV}$ bigger in the epileptic neurons comparing with those in control, and this difference was independent of ongoing epileptiform activity.

\section{DISCUSSION}

The principal finding of the present study is that bumetanide reduces $\mathrm{DF}_{\mathrm{GABA}}$ and blocks seizures in the mirror focus, suggesting that the excitatory action of GABA, mediated at large by NKCC1, is critically important for the generation of epileptiform activity. However, bumetanide does not prevent the seizure-dependent transformation of a naïve network to the epileptic one, suggesting that seizures beget seizures even when NKCC1 is not functioning. In addition, a residual increase in $\mathrm{DF}_{\mathrm{GABA}}$ in the presence of bumeta- 


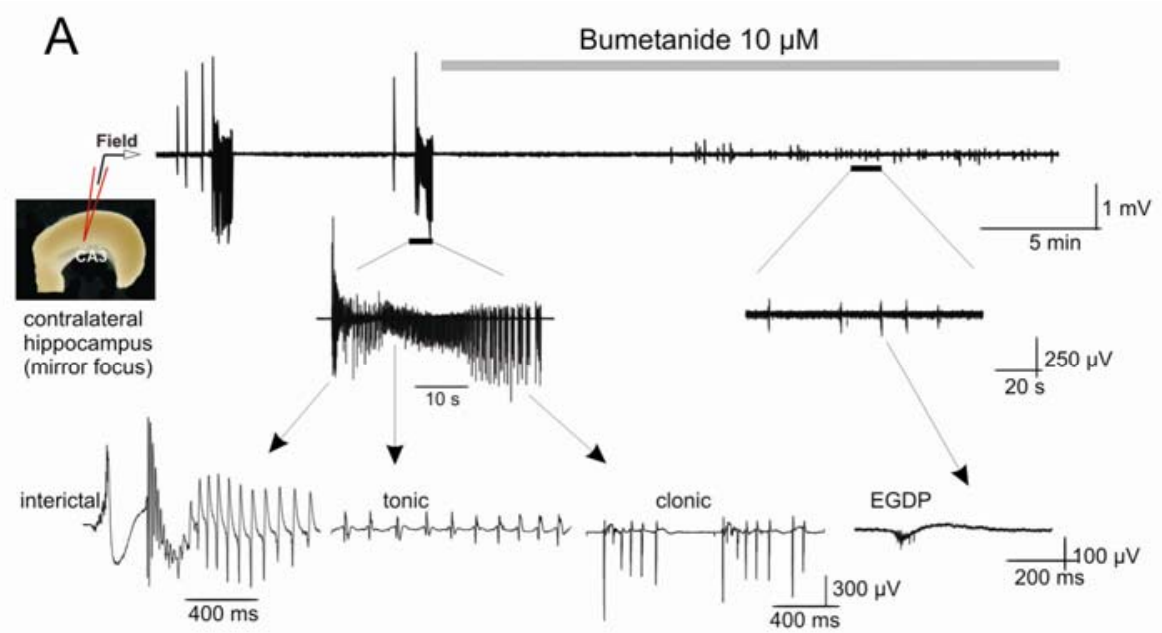

FIG. 5. Bumetanide blocks seizures in the mirror focus. Field recordings in the separated contralateral intact hippocampus $(A)$ and slices obtained from the contralateral hippocampus $(B)$ after mirror focus formation. Note that seizures have been blocked by bumetanide and replaced by spontaneous (GDP-like) population events (see Fig. 6).
B

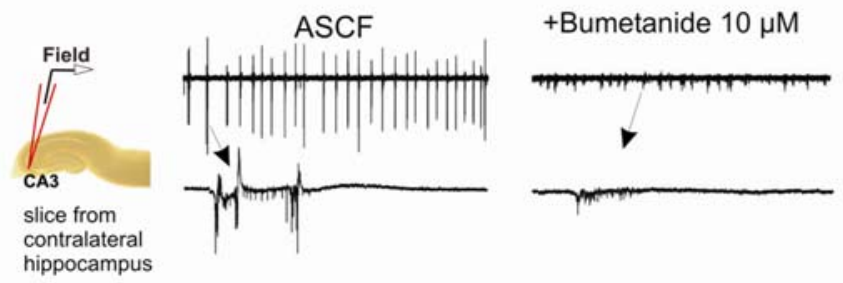

nide indicates that a persistent elevation of $\left[\mathrm{Cl}^{-}\right]_{\mathrm{i}}$ in the epileptic neurons is only partially mediated by NKCC1.

\section{Bumetanide is an anticonvulsive but not an antiepileptogenic agent}

The effects of bumetanide on seizures are quite controversial depending on the type of model and convulsive agent used. Bumetanide reduced seizures generated by high $\mathrm{K}^{+}$(Dzhala et al. 2005; Kilb et al. 2007), reduced (Dzhala et al. 2008) or increased (Kilb et al. 2007) seizures generated by low $\mathrm{Mg}^{2+}$, and augmented the frequency of seizures generated by kainate (Kilb et al. 2007). Delpire and colleagues (Zhu et al. 2008) suggested that NKCC1 antagonists aggravate 4-aminopyridine-induced seizures and enhance neuronal excitability, albeit at a later developmental stage (P10-P13), and also suggested that NKCC1 actually reduces hyperexcitability.

We found that bumetanide neither reduced nor aggravated the severity of seizures in both kainate-treated hippocampus and contralateral hippocampus to which these seizures propagated and failed also to prevent formation of the epileptogenic mirror focus. Bumetanide did not block the high-frequency components of seizures $(>40 \mathrm{~Hz})$, which are critically important for the formation of mirror focus (Khalilov et al. 2005). It also did not alter GABAmediated PSCs during ictal events generated by the propagation of seizures from the kainate-treated hippocampus. In contrast, GABA receptor antagonists block the HFOs and mirror focus formation (Khalilov et al. 2005) confirming that functional GABA signaling is essential for these events.

In spite of a $\mathrm{DF}_{\mathrm{GABA}}$ reduction by bumetanide in naïve neurons of to the levels close to $E_{\mathrm{m}}$, the dynamic accumulation of chloride during severe seizures is not fully controlled by NKCC1.

Therefore it is likely that during recurrent seizures the severity of

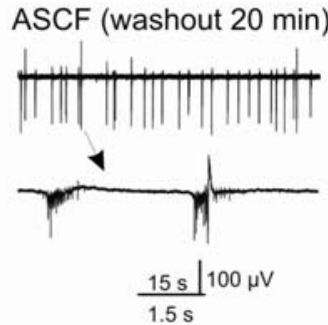

ictal events and the GABA-mediated massive influx of chloride overcome the inhibitory effect of bumetanide on NKCC1 and $\left[\mathrm{Cl}^{-}\right]_{\mathrm{i}}$ accumulation. Dynamic effects of seizures on $\mathrm{DF}_{\mathrm{GABA}}$, that is likely neuronal type dependent, and the mechanisms of chronic alteration of $\mathrm{DF}_{\mathrm{GABA}}$ by seizures remain to be further investigated.

In contrast, bumetanide fully blocked generation of seizures in the disconnected mirror focus although the GDP-like pattern, EGDPs, still remained. Its properties, however, differed significantly from those of interictal events.

Determining the mechanisms underlying the chronic alterations of $\left[\mathrm{Cl}^{-}\right]_{\mathrm{i}}$ in epileptic tissues is important because most antiepileptic drugs (AEDs) have been developed using adult experimental models that do not possess the unique properties of immature neurons and networks (Connell et al. 1989; Painter et al. 1999; Staley 2008). It has been suggested that drugs that reduce $\left[\mathrm{Cl}^{-}\right]_{\mathrm{i}}$ such as bumetanide may constitute a novel family of AEDs adapted to developmental epilepsies (Dzhala et al. 2008; Kahle and Staley 2008b). Our observations, however, suggest that although bumetanide blocks the expression of seizures, it may not be efficient in preventing the longlasting sequels of recurrent seizures. This is particularly important because seizures in neonates can cause long-lasting deteriorate effects (Ben-Ari 1985; Hauser et al. 1998; Levene 2002; Massingale and Buttross 1993; Mizrahi and Clancy 2000; Moshe and Albala 1982; Tremblay et al. 1984).

NKCC1 is partly responsible for the persistent increase of $\mathrm{DF}_{\mathrm{GABA}}$ in epileptic neurons

Previous studies consistently showed that bumetanide reduces $\left[\mathrm{Cl}^{-}\right]_{\mathrm{i}}$ and the excitatory actions of GABA in immature neurons (Dzhala et al. 2005; Sipila et al. 2006; Yamada et al. 2004). However, these studies used invasive recording techniques-whole 


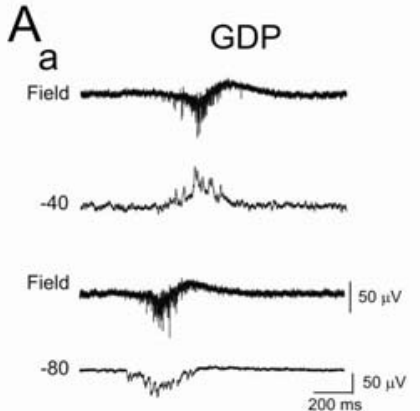

b

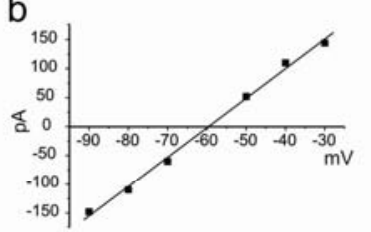

C

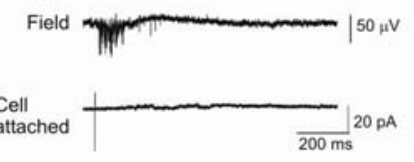

D

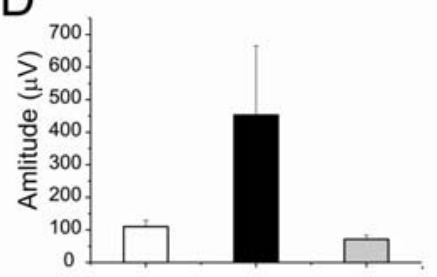

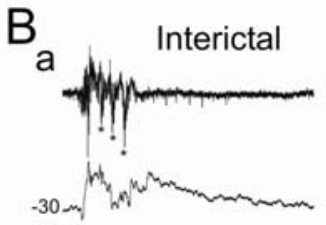

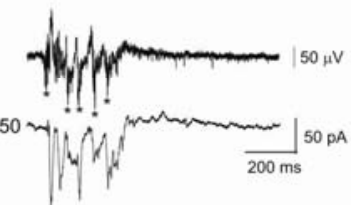

b

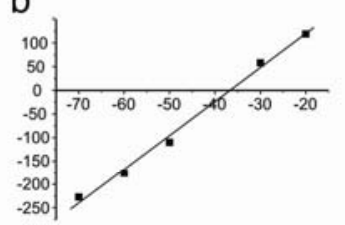

C

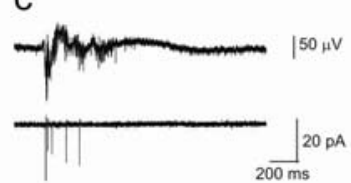

E

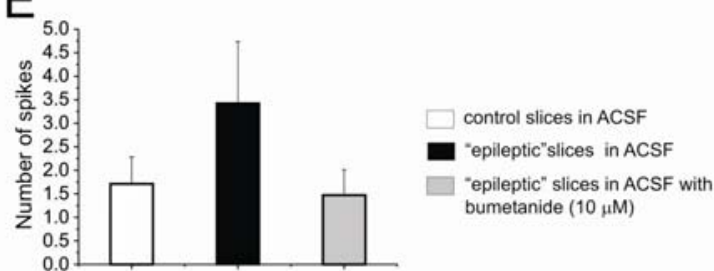

FIG. 6. Bumetanide transforms seizure activity into the GDP-like recurrent population bursts. Simultaneous extracellular and gramicidine perforated-patch recordings of spontaneous synchronized network activity in control slices $(A)$, mirror focus slices $(B)$, and mirror focus slices in the presence of bumetanide (C). $A b, B b$, and $C b: I-V$ relations of perforated-patch currents. $A c, B c$, and $C c$ : simultaneous extracellular and cell-attached recordings of spontaneous network activity in control, mirror focus slices, and mirror focus slices in the presence of bumetanide. $D$ : summary plot of mean amplitudes of field potentials during synchronized network events. $E$ : the mean number of cell-attached recorded spikes during this synchronized activity. cell and perforated-patch recordings-that strongly alter resting membrane potential (Tyzio et al. 2003). Here we used for the first time single channel recordings to determine the actions of bumetanide on both $E_{\mathrm{m}}$ and $E_{\mathrm{GABA}}$ and thus the driving force of GABA $D F_{G A B A}$. Our results indicate that bumetanide clearly reduces significantly $E_{\mathrm{GABA}}$ leading to an important fall in the driving force of GABA and confirming the actions of the diuretic compound on intracellular chloride and $E_{\mathrm{GABA}}$. The small change of $E_{\mathrm{m}}$ in epileptic neurons when compared with controls as determined with single NMDA channel recordings may be due to tonic $\mathrm{GABA}_{\mathrm{A}}$ current (Sipila et al. 2005) that causes increased membrane depolarization due to depolarizing $\mathrm{DF}_{\mathrm{GABA}}$. But we did not investigate further this issue. We also did not investigate possible distal actions of bumetanide on the dendrites of pyramidal neurons or on other neuronal populations.

Enhancement of $\left[\mathrm{Cl}^{-}\right]_{\mathrm{i}}$ in the mirror focus neurons was significantly reduced by bumetanide

However, under action of bumetanide, $\mathrm{DF}_{\mathrm{GABA}}$ in the epileptic neurons was still bigger than in control $(>10$ and $2 \mathrm{mV}$, respectively). Although the upregulation of NKCC1 expression in epileptic mirror focus neurons cannot be excluded (Okabe et al. 2002), the increase in bumetanide concentration has not reduced $\left[\mathrm{Cl}^{-}\right.$ ]$_{i}$ further, suggesting that other mechanisms are involved. One possible candidate is the KCC2 that is thought to play a fundamental role in $\mathrm{Cl}^{-}$extrusion (Hubner et al. 2001; Lee et al. 2005; Rivera et al. 1999). It is well documented that KCC2 expression in rodents is low at birth in the forebrain and increases steadily during the first 23 wk of postnatal life (Clayton et al. 1998; Dzhala et al. 2005; Lu et al. 1999; Mikawa et al. 2002; Rivera et al. 1999; Wang et al. 2002). Seizures and other insults can induce a downregulation of KCC2 expression (de et al. 2006; Fiumelli et al. 2005; Palma et al. 2006; Payne et al. 2003; Rivera et al. 2004).

However, to the best of our knowledge, little information is available on the functionality of KCC2 at an early developmental stage. We cannot also exclude a participation of voltage-gated $\mathrm{Cl}^{-}$ channels to the chloride homeostasis (Farrant and Kaila 2007; Huguenard and Alger 1986; Ling and Benardo 1995; McCarren and Alger 1985; Payne et al. 2003; Staley et al. 1996; Thompson and Gähwiler 1989).

In conclusion, our study with the use of noninvasive single channel recordings in chronic epileptic tissue, confirms the importance of evaluation of $\mathrm{DF}_{\mathrm{GABA}}$ and $E_{\mathrm{m}}$ to examine the effects of seizures and putative anticonvulsive agents on neuronal network functioning. Our observations are in favor of using bumetanide for blocking seizures in neonates but also call for studies of other regulators of intracellular chloride and their effects on seizures.

Although a strict comparison with the clinical situation is difficult because of the large variety of epilepsy types and longlasting duration required for seizures to evoke their neurological sequels, we consider the mirror focus as an "epileptic" tissue because it generates spontaneously recurrent ictal and interictal seizures for hours and up to 2 days [the longest period this preparation could be kept (Khalilov et al. 2003)]. It has been suggested that a combination of phenobarbital and bumetanide is more efficient for treating refractory infantile epilepsies because bumetanide reduces $\mathrm{DF}_{\mathrm{GABA}}$ and phenobarbital augments the efficacy of inhibitory GABA 
A

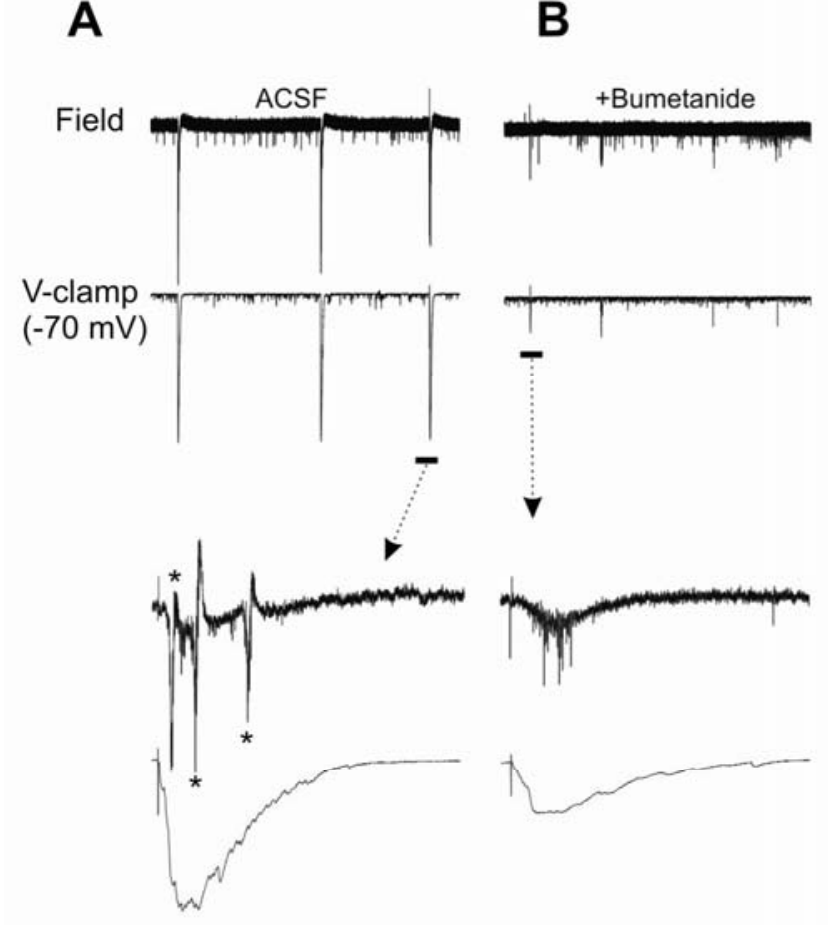

C
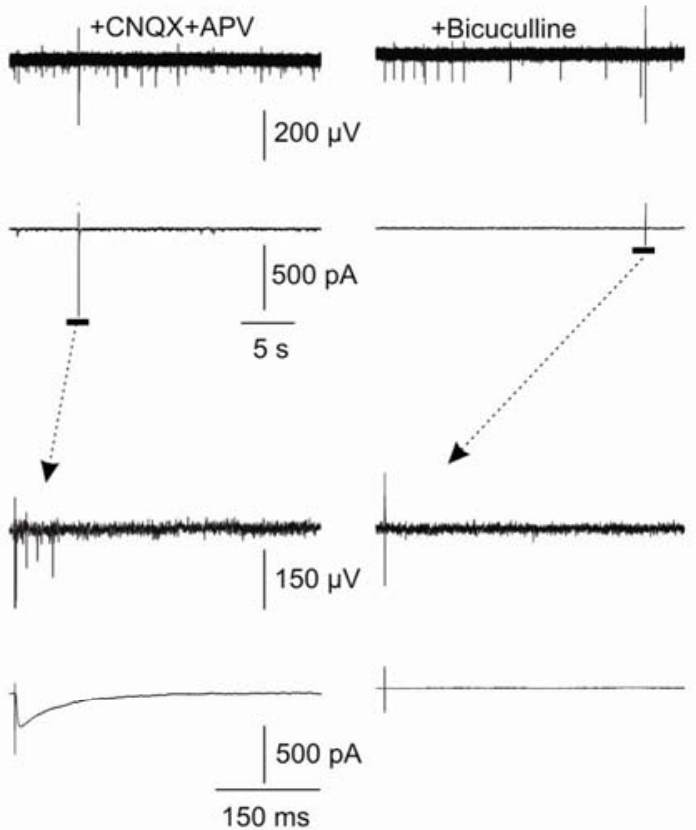

$\mathbf{E}$

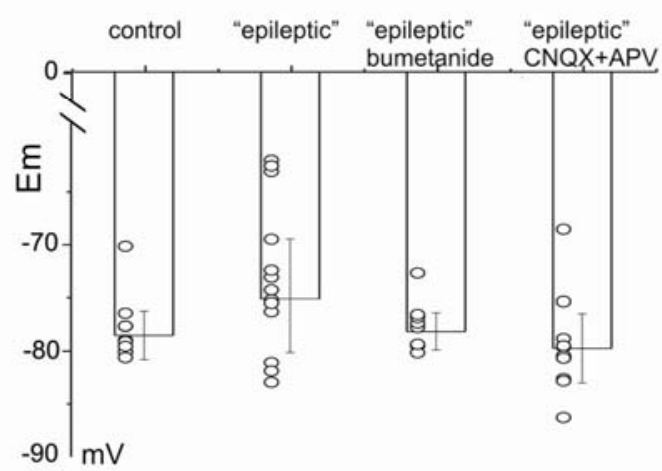

$\mathbf{F}$

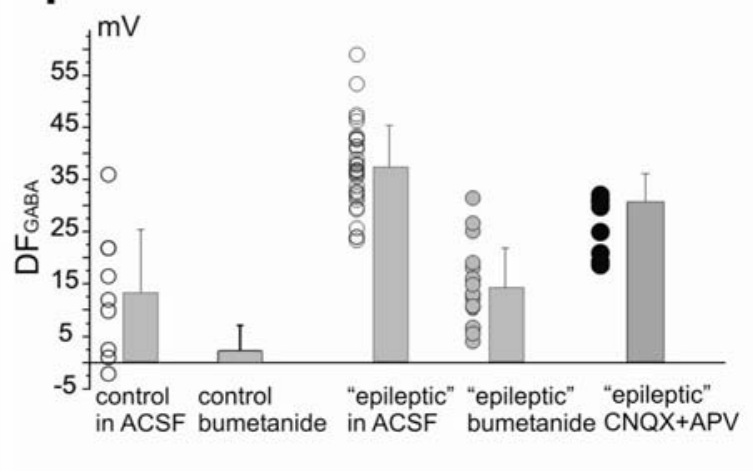

FIG. 7. Bumetanide reduces only partially the positive $\mathrm{DF}_{\mathrm{GABA}}$ in epileptogenic focus. $A-D$ : simultaneous extracellular and whole cell recordings of evoked and spontaneous activities in epileptic slices obtained from the contralateral hippocampus after mirror focus formation. Note that bumetanide blocked interictal-like epileptiform events $(B)$ but did not completely block the excitatory action of GABA $(C$ and $D)$. Resting membrane potentials $\left(E_{\mathrm{m}}\right)$ measured with single NMDA receptor channels $(E)$ and $\mathrm{DF}_{\mathrm{GABA}}$ measured with single $\mathrm{GABA}_{\mathrm{A}}$ receptor channels $(F)$ in control and epileptic slices.

signaling (Dzhala et al. 2008; Kahle and Staley 2008b). The validity of this attractive hypothesis will depend, however, on the contribution of NKCC1 to positive $\mathrm{DF}_{\mathrm{GABA}}$ in epileptic conditions.

\section{ACKNOWLEDGMENTS}

We thank Dr. Yuri Zilberter, Dr. Rustem Khazipov and Dr. Matthew T. Colonnese for their suggestions and criticism.

\section{GRANTS}

We are indebted for financial support to Institut National de la Santé et de la Recherche Médicale, Ligue Francçaise contre l'épilepsie Conseil Régional Provence Alpes Côte d'Azur. Fédération de la recherche médicale, and the Assistance Publique des Hôpitaux de Paris to Y. Ben-Ari and the Fédération de la recherche sur le cerveau. 


\section{REFERENCES}

Ben-Ari Y. Limbic seizure and brain damage produced by kainic acid: mechanisms and relevance to human temporal lobe epilepsy. Neuroscience 14: 375-403, 1985.

Ben-Ari Y. Excitatory actions of GABA during development: the nature of the nurture. Nat Rev Neurosci 3: 728-739, 2002.

Ben-Ari Y, Cherubini E, Corradetti R, Gaïarsa J-L. Giant synaptic potentials in immature rat CA3 hippocampal neurones. J Physiol 416: 303 325, 1989.

Ben-Ari Y, Gaiarsa JL, Tyzio R, Khazipov R. GABA: a pioneer transmitte that excites immature neurons and generates primitive oscillations. Physiol Rev 87: 1215-1284, 2007.

Brumback AC, Staley KJ. Thermodynamic regulation of NKCC1-mediated $\mathrm{Cl}$ - cotransport underlies plasticity of GABA(A) signaling in neonatal neurons. J Neurosci 28: 1301-1312, 2008.

Clayton GH, Owens GC, Wolff JS, Smith RL. Ontogeny of cation-Clcotransporter expression in rat neocortex. Brain Res Dev Brain Res 109: 281292, 1998.

Cohen I, Navarro V, Clemenceau S, Baulac M, Miles R. On the origin of interictal activity in human temporal lobe epilepsy in vitro. Science 298: 1418-1421, 2002.

Connell J, Oozeer R, Devries L, Dubowitz LMS, Dubowitz V. Clinical and EEG response to anticonvulsants in neonatal seizures. Arch Dis Childhood 64: 459-464, 1989

de GP, Inaba Y, Biagini G, Baldelli E, Mollinari C, Merlo D, Avoli M. Subiculum network excitability is increased in a rodent model of temporal lobe epilepsy. Hippocampus 16: 843-860, 2006.

Dzhala VI, Brumback AC, Staley KJ. Bumetanide enhances phenobarbital efficacy in a neonatal seizure model. Ann Neurol 63: 222-235, 2008.

Dzhala VI, Staley KJ. Excitatory actions of endogenously released GABA contribute to initiation of ictal epileptiform activity in the developing hippocampus. J Neurosci 23: 1840-1846, 2003.

Dzhala VI, Talos DM, Sdrulla DA, Brumback AC, Mathews GC, Benke TA, Delpire E, Jensen FE, Staley KJ. NKCC1 transporter facilitates seizures in the developing brain. Nat Med 11: 1205-1213, 2005.

Farrant M, Kaila K. The cellular, molecular and ionic basis of GABA(A) receptor signalling. Prog Brain Res 160: 59-87, 2007.

Fiumelli H, Cancedda L, Poo MM. Modulation of GABAergic transmission by activity via postsynaptic $\mathrm{Ca}^{2+}$-dependent regulation of KCC2 function. Neuron 48: 773-786, 2005.

Fujiwara-Tsukamoto Y, Isomura Y, Imanishi M, Fukai T, Takada M. Distinct types of ionic modulation of GABA actions in pyramidal cells and interneurons during electrical induction of hippocampal seizure-like network activity 2. Eur J Neurosci 25: 2713-2725, 2007.

Hauser WA. Epidemiology of epilepsy in children. Neurosurg Clin N Am 6: 419-429, 1995.

Hauser WA, Rich SS, Lee JR, Annegers JF, Anderson VE. Risk of recurrent seizures after two unprovoked seizures. N Engl J Med 338: 429434, 1998.

Holmes GL, Ben-Ari Y. Seizures in the developing brain: perhaps not so begin after all. Neuron 21: 1231-1234, 1998.

Huberfeld G, Wittner L, Clemenceau S, Baulac M, Kaila K, Miles R, Rivera C. Perturbed chloride homeostasis and GABAergic signaling in human temporal lobe epilepsy 1. J Neurosci 27: 9866-9873, 2007.

Hubner CA, Stein V, Hermans-Borgmeyer I, Meyer T, Ballanyi K, Jentsch TJ. Disruption of KCC2 reveals an essential role of K-Cl cotransport already in early synaptic inhibition. Neuron 30: 515-524, 2001.
Huguenard JR, Alger BE. Whole-cell voltage-clamp study of the fading of GABA-activated currents in acutely dissociated hippocampal neurons. $J$ Neurophysiol 56: 1-18, 1986.

Jin X, Huguenard JR, Prince DA. Impaired $\mathrm{Cl}^{-}$extrusion in layer V pyramidal neurons of chronically injured epileptogenic neocortex. $J$ Neurophysiol 93: 2117-2126, 2005.

Kahle KT, Staley K. Altered neuronal chloride homeostasis and excitatory GABAergic signaling in human temporal lobe epilepsy. Epilepsy Curr 8: 51 53, 2008a.

Kahle KT, Staley KJ. The bumetanide-sensitive Na-K-2Cl cotransporter NKCC1 as a potential target of a novel mechanism-based treatment strategy for neonatal seizures. Neurosurg Focus 25: E22, 2008b.

Khalilov I, Dzhala V, Medina I, Leinekugel X, Melyan Z, Lamsa K, Khazipov R, Ben-Ari Y. Maturation of kainate-induced epileptiform activities in interconnected intact neonatal limbic structures in vitro. Eur $J$ Neurosci 11: 3468-3480, 1999.

Khalilov I, Esclapez M, Medina I, Aggoun D, Lamsa K, Leinekugle X, Khazipov R, BenAri Y. A novel in vitro preparation: the intact hippocampal formation. Neuron 19: 743-749, 1997.

Khalilov I, Holmes GL, Ben Ari Y. In vitro formation of a secondary epileptogenic mirror focus by interhippocampal propagation of seizures. Nat Neurosci 6: 1079-1085, 2003.

Khalilov I, Van Quyen M, Gozlan H, Ben Ari Y. Epileptogenic actions of GABA and fast oscillations in the developing hippocampus. Neuron 48: 787796, 2005.

Khazipov R, Khalilov I, Tyzio R, Morozova E, Ben-Ari Y, Holmes GL. Developmental changes in GABAergic actions and seizure susceptibility in the rat hippocampus. Eur J Neurosci 19: 590-600, 2004.

Kilb W, Sinning A, Luhmann HJ. Model-specific effects of bumetanide on epileptiform activity in the in-vitro intact hippocampus of the newborn mouse. Neuropharmacology 53: 524-533, 2007.

Lee H, Chen CX-Q, Liu YJ, Aizenman E, Kandler K. KCC2 expression in immature rat cortical neurons is sufficient to switch the polarity of GABA responses. Eur J Neurosci 21: 2593-2599, 2005.

Levene M. The clinical conundrum of neonatal seizures 15. Arch Dis Childhood 86: 75-77, 2002.

Ling DS, Benardo LS. Activity-dependent depression of monosynaptic fast IPSCs in hippocampus: contributions from reductions in chloride driving force and conductance. Brain Res 670: 142-146, 1995.

Lu J, Karadsheh M, Delpire E. Developmental regulation of the neuronalspecific isoform of $\mathrm{K}-\mathrm{Cl}$ cotransporter KCC2 in postnatal rat brains. $J$ Neurobiol 39: 558-568, 1999.

Massingale TW, Buttross S. Survey of treatment practices for neonatal seizures. J Perinatol 13: 107-110, 1993.

McCarren M, Alger BE. Use-dependent depression of IPSPs in rat hippocampal pyramidal cells in vitro. J Neurophysiol 53: 557-571, 1985.

Mikawa S, Wang C, Shu F, Wang T, Fukuda A, Sato K. Developmental changes in KCC1, KCC2 and NKCC1 mRNAs in the rat cerebellum. Brain Res Dev Brain Res 136: 93-100, 2002.

Mizrahi EM, Clancy RR. Neonatal seizures: early-onset seizure syndromes and their consequences for development. Ment Retard Dev Disabil Res Rev 6 : 229-241, 2000.

Moshe SL, Albala BJ. Kindling in developing rats: persistence of seizures into adulthood. Brain Res 256: 67-71, 1982.

Moshe SL, Albala BJ, Ackermann RF, Engel JJ. Increased seizures susceptibility of the immature brain. Dev Brain Res 7: 81-85, 1983. 
Okabe A, Ohno K, Toyoda H, Yokokura M, Sato K, Fukuda A. Amygdala kindling induces upregulation of mRNA for NKCC1, a $\mathrm{Na}(+), \mathrm{K}(+)-2 \mathrm{Cl}(-)$ cotransporter, in the rat piriform cortex. Neurosci Res 44: 225-229, 2002.

Painter MJ, Scher MS, Stein AD, Armatti S, Wang ZM, Gardiner JC, Paneth N, Minnigh B, Alvin J. Phenobarbital compared with phenytoin for the treatment of neonatal seizures. N Engl J Med 341: 485-489, 1999.

Palma E, Amici M, Sobrero F, Spinelli G, Di Angelantonio S, Ragozzino D, Mascia A, Scoppetta C, Esposito V, Miledi R, Eusebi F. Anomalous levels of Cl- transporters in the hippocampal subiculum from temporal lobe epilepsy patients make GABA excitatory. Proc Natl Acad Sci USA 103: 8465-8468, 2006.

Payne JA, Rivera C, Voipio J, Kaila K. Cation-chloride co-transporters in neuronal communication, development and trauma. Trends Neurosci 26: 199206, 2003.

Rivera C, Voipio J, Payne JA, Ruusuvuori E, Lahtinen H, Lamsa K,

Pirvola U, Saarma M, Kaila K. The $\mathrm{K}^{+} / \mathrm{Cl}$ - co-transporter KCC2 renders GABA hyperpolarizing during neuronal maturation. Nature 397: 251-255, 1999.

Rivera C, Voipio J, Thomas-Crusells J, Li H, Emri Z, Sipila S, Payne JA, Minichiello L, Saarma M, Kaila K. Mechanism of activity-dependent downregulation of the neuron-specific K-Cl cotransporter KCC2. J Neurosci 24: 4683-4691, 2004.

Shimizu-Okabe C, Yokokura M, Okabe A, Ikeda M, Sato K, Kilb W, Luhmann HJ, Fukuda A. Layer-specific expression of Cl- transporters and differential [Cl-]i in newborn rat cortex. Neuroreport 13: 2433-2437, 2002.

Sipila ST, Huttu K, Soltesz I, Voipio J, Kaila K. Depolarizing GABA acts on intrinsically bursting pyramidal neurons to drive giant depolarizing potentials in the immature hippocampus. J Neurosci 25: 5280-5289, 2005.
Sipila ST, Schuchmann S, Voipio J, Yamada J, Kaila K. The Na-K-Cl cotransporter (NKCC1) promotes sharp waves in the neonatal rat hippocampus. J Physiol 573: 765-773, 2006.

Staley KJ. Does Plasticity of the GABA(A) reversal potential contribute to epileptogenesis? Epilepsy Curr 8: 107-110, 2008.

Staley K, Smith R, Schaack J, Wilcox C, Jentsch TJ. Alteration of $\mathrm{GABA}_{\mathrm{A}}$ receptor function following gene transfer of the CLC-2 chloride channel. Neuron 17: 543-551, 1996.

Thompson SM, Gähwiler BH. Activity-dependent disinhibition. I. Repetitive stimulation reduces IPSP driving force and conductance in the hippocampus in vitro. J Neurophysiol 61: 501-511, 1989.

Tremblay E, Nitecka L, Berger ML, Ben-Ari Y. Maturation of kainic acid seizure-brain damage syndrome in the rat. I. Clinical, electrographic and metabolic observations. Neuroscience 13: 1051-1072, 1984.

Tyzio R, Ivanov A, Bernard C, Holmes GL, Ben Ari Y, Khazipov R. Membrane potential of CA3 hippocampal pyramidal cells during postnatal development. J Neurophysiol 90: 2964-2972, 2003.

Wang C, Shimizu-Okabe C, Watanabe K, Okabe A, Matsuzaki H, Ogawa T, Mori N, Fukuda A, Sato K. Developmental changes in KCC1, KCC2, and NKCC1 mRNA expressions in the rat brain. Brain Res Dev Brain Res 139: 59-66, 2002.

Yamada J, Okabe A, Toyoda H, Kilb W, Luhmann HJ, Fukuda A. Cluptake promoting depolarizing GABA actions in immature rat neocortical neurones is mediated by NKCC1. J Physiol 557: 829-841, 2004.

Zhu L, Polley N, Mathews GC, Delpire E. NKCC1 and KCC2 prevent hyperexcitability in the mouse hippocampus. Epilepsy Res 79: 201-212, 2008. 